\title{
Celebrating the data revolution
}

\author{
Two innovations in photonics that underpin society's adoption of information technology have been \\ honoured in this year's Nobel Prize for Physics.
}

The 2009 Nobel Prize for Physics has honoured three scientists who carried out pioneering research in the development of the low-loss optical fibre and the CCD image sensor. Half of this year's prize goes to Charles Kao, who in the mid-1960s had an important role in demonstrating that the use of clad silica-glass fibre was a viable means of long-distance data communication. The other half is shared between Willard Boyle and George Smith, the two scientists who devised and built the CCD image sensor at Bell Labs in the early 1970s.

Of course, it's not the first time that important achievements in photonics have been deemed worthy of the Nobel Prize for Physics. In 2005, Roy Glauber, John Hall and Theodor Hänsch shared the prize for the quantum theory of coherence and frequency-comb spectroscopy. Earlier, in 1997, Steven Chu, Claude Cohen-Tannoudji and William Phillips were collectively awarded the prize for their work on the cooling of atoms using laser light. And of course, there are many other examples prior to these.

What is particularly interesting about this year's choice of award is the strongly applied nature of the achievements and the prevalence of the technologies in today's society. Indeed, this is probably one of the rare instances where many of those working outside science are likely to have both an immediate familiarity with the topics of the award and an appreciation of their usefulness. After all, in developed countries fibre-optic communications underpin phone networks and the internet, and digital cameras are now considered a ubiquitous item in many households.

In effect, the award recognizes a triumph in information technology: the ability to capture and transmit vast amounts of digital information around the globe, at will. What's astonishing is the speed of progress since the initial studies of Kao, Boyle and Smith.

In the early 1960s, Kao was a young researcher at the Standard Telecommunications Laboratories (which later became the research laboratories of the telecommunications giant Nortel) in Harlow, UK. At that time, an optical fibre suitable for data transmission did not exist and many believed it to be out of reach ${ }^{1}$.

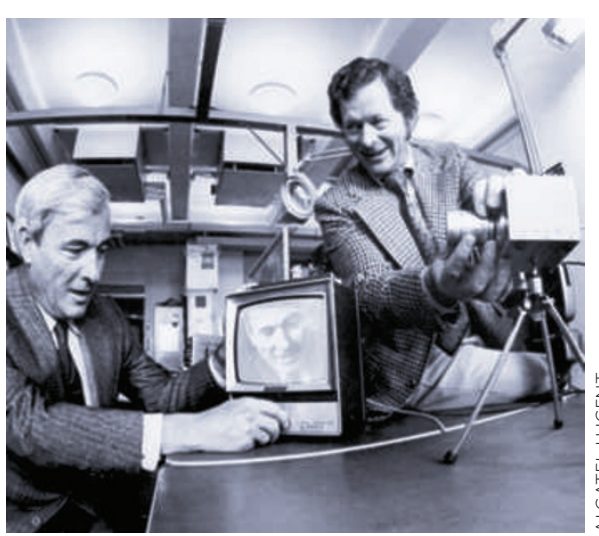

fibre is around $0.15 \mathrm{~dB} \mathrm{~km}^{-1}$ and fibre-optic links span across oceans, carrying terabits of data every second.

The development of the CCD sensor came at around the same time as Kao's research into optical fibres. Bell Labs gave Boyle and Smith the task of developing the electronic camera technology needed for a video telephone service it was investigating. On 17 October 1969, the two scientists sat down and designed the basic structure of an image sensor that they believed would be suitable, and the following year its design and initial experimental results were presented in the Bell Systems Technical Journal $^{3,4}$. The idea was to use metal-oxide

The key problem was in the early prototype glass waveguide designs, which suffered from extremely high attenuation (as high as $1,000 \mathrm{~dB} \mathrm{~km}^{-1}$ ), making them completely impractical for transmitting light more than a few centimetres.

Together with his colleague George Hockham, Kao's research into the origin of the loss revealed that it was caused by light absorption and scattering, suggesting that if impurities in the glass could be reduced, a low-loss window suitable for data transmission could be realized.

In a landmark paper published in June 1966 entitled "Dielectric fibre surface waveguides for optical frequencies" ${ }^{\text {, the }}$ duo predicted with great foresight that silica-clad single-mode fibres could be a practical and important new method of communication - a method feasible with existing lasers and detectors if the fibre loss could be reduced to around $20 \mathrm{~dB} \mathrm{~km}^{-1}$.

The paper inspired intense research worldwide to find ways of making purer glass, and within just a few years researchers at the US firm Corning had developed a technique called chemical vapour deposition, making it possible to fabricate fused-silica fibres that had losses of just a few tens of decibels per kilometre. In 1973, the Harlow team had constructed a transmission set-up that spanned $2 \mathrm{~km}$, using fibre with a loss of $25 \mathrm{~dB} \mathrm{~km}^{-1}$. By 1977 , the loss had been reduced to just $5 \mathrm{~dB} \mathrm{~km}^{-1}$. British Telecom installed a field trial between the towns of Hitchin and Stevenage in the UK using this fibre, and successfully passed voice traffic over the link. Today, the loss of a commercial optical semiconductor technology (which had only recently been developed) to create a light-sensitive sensor containing an array of pixels. Each pixel could store light-induced charge, the magnitude of which could be read by shifting the charge to the edge of the device - where it would be measured by readout electronics - after exposure was complete. By 1970, Boyle and Smith had built the world's first solid-state camera, and by 1975 they had produced a version with an image quality suitable for broadcast television. Since then, CCD sensors have evolved to become an essential imaging technology for a wide range of scientific instruments in fields such as bio-imaging, astronomy and satellite imaging. More recently, the consumer applications of CCD image sensors have grown dramatically, with small sensors finding their way into digital cameras, video cameras, fax machines, scanners and photocopiers. Furthermore, the sensitivity of CCD sensors has improved to the single-photon level, and the number of pixels found on a sensor has grown to the extent that even basic digital cameras now feature 10 million pixels or more.

It will be interesting to see if this year's Nobel Prize for Physics will set a precedent, allowing applied and technology-oriented developments in photonics to be recognized in future awards.

\footnotetext{
References

1. Hecht, J. City of Light: The Story of Fiber Optics. (Oxford University Press, 1999).

2. Kao, K. C \& Hockham, G. A. Proc. IEE 113, 1151-1158 (1966).

3. Boyle, W. S. \& Smith, G. E. Bell Syst. Tech. J. 49, 587-593 (1970).

4. Amelio, G. F., Tompsett, M. F. \& Smith, G. E. Bell Syst. Tech. J. 49, 593-600 (1970).
} 